\title{
Design and Development of a Smart Weighing Scale for Sugar Mill
}

\author{
Anusha Mudgal, \\ Anuradha Kumari \\ Department of Computer \\ Science and Engineering \\ Meerut Institute of Engineering \\ and Technology \\ Meerut U.P.250001
}

\author{
Apoorv Mittal, Archit \\ Agarwal \\ Department of Computer \\ Science and Engineering \\ Meerut Institute of Engineering \\ and Technology \\ Meerut U.P.250001
}

\author{
Vishal Choudhary \\ Department of Computer \\ Science and Engineering \\ Meerut Institute of Engineering \\ and Technology \\ Meerut U.P.250001
}

\begin{abstract}
Nowadays, sugar mills use manual techniques to operate many of its functioning. Sugar Mills gave the slip to the farmers which are used for accounting the weight of the sugarcane and the price of the sugarcane so this process is time taking and if the slip got misplaced it is a very hectic process for both the parties. So, we want to automate this process by making very convenient and easy for the farmers to use. The application requires sugar mills weights sugarcane manually in which there is a lot of cases of frauds, so we automate this process with the help of the IoT weighing Scale, in this application we use Load Cell for weighing and by WiFi module will help to automatically update the details online. Also, we got the database server to store all intermediate results and also we can delete all results. There is a load cell by using; I can measure up to $2 \mathrm{~kg}$ weight. Firstly this weight goes to ADC (analog to digital converter) to convert the weight into digital weight, after that this weight will go to the microcontroller for controlling all weight and display on the led, through Wi-Fi module, here we use power plug source to get the electricity.
\end{abstract}

\section{General Terms}

This application can further be used by Sugar Mill Industries in the weighing of sugarcanes easily by IoT application and hence it can be very beneficial for them. Now a days precise measurement and storage of weight are one of the most important activities in industries. The mechanical weighing machines are now replaced by the electronics weighing machine as electronic weighing machines are smart with the advantages like accuracy, reliability, and a wide range [4], smart homes [5], and security [6].

\section{Keywords}

Digital weighing machine; Load Cell; Internet of Things (IoT); HX711; Circuit Diagram

\section{INTRODUCTION}

In the world, the fourth major sugar-producing country is India.[1] In India, the sugar industry occupies an important place among organized industries and is one of the largest agro-based industries in rural India. A large mass of sugarcane farmers, mills depend on it and a large no. of laborers were involved in sugarcane cultivation and many other significant activities, which constitutes in the rural population of the country [2].

In today's scenario sugar industries are using simple weighing scales to weight sugarcanes and then manage the entries manually but we want to replace weighing scales with IOT based weighing sensors by which we directly update the weight of sugarcane on the server.

Weighing machines are a very useful product. Moreover, the Weighing machine is used in many industrial and commercial applications. The analog weighing system is very erroneous. In a digital weighing machine, we don't have to face any problem. Only viewing the display we come to know the exact weight of the product [3].

\subsection{Scope}

In a digital weighing machine, we interface with the digital world. In this project, come to know about the basic knowledge used for designing a digital weighing machine and know how to help others in a weighing with a digital weight machine easily and cheaply. This project helps us to compete with the Manufacturer Company of the digital weighing machine in the future.

In this paper, a solution presents the software and hardware design, results and conclusion. In many shops just by placing an item on the weighing platform and the weight, machines display the weight. So here we are building some digital concept where the Weighing machine used to weigh goods in the crate itself by using Arduino and Load cells, having the capacity of measuring up to $2 \mathrm{~kg}$. This limit can be further increased by using the Load cell of higher capacity. [7]. After a comprehensive survey of available weighing devices to weigh sugarcanes, as we say nowadays, sugar mills used manual techniques to operate many of its functioning. Sugar Mills gave the slip to the farmers which are used for accounting the weight of the sugarcane and the price of the sugarcane so this process is time taking and if the slip got misplaced it is a very hectic process for both the parties. So, we want to automate this process by making very convenient and easy for the farmers to use.

\section{RELATED WORK}

In 1977 sugarcane weight, an example of an early scientific study [8]. The mechanical scale is used for high precision and used for modification, including protecting the mechanical components from rust. For the changing values used an elaborate vision system. Non-invasive weight measurement was one of the earlier implementations i.e. the scale was integrated into the system, rather than attached at selected periods. The scale became part of the weighing. The scale had an accuracy of about $0.5 \mathrm{~kg}$ and for the research groups' study, it provided reliable data. Researchers travelled to the mills and recorded the weight on an hourly basis, over 3 years. 
Advances in the development of load cells, pressure sensors, and $\mathrm{Wi}-\mathrm{Fi}$ modules have made these technologies more attractive for use in weight measuring applications. Load cells have become a standard in weighing systems. In the application of a single, robust load cell used to weigh an entire weight [10], the maximum weight the load cell can accommodate is $2 \mathrm{~kg}$, which satisfies the requirements of an average-sized.

Previously, weight measurement depended greatly on researchers traveling to the mill site and manually recording the value displayed on the mechanical balance [9].

We required a lot of time for Recordings, which was hectic and need a lot of additional attention. The recent development in technology has significantly reduced the need for site visits. The advent of data logger technology has removed the necessity to manually monitor the weight as it can automatically record the changes over time. The accumulated data can then be collected at less frequent intervals.

\subsection{Features}

[1] High speed of response, low settling time and hence rapid weighing.

[2] Compact and small in size.

[3] Both analog and digital output with printing Easy to operate.

[4] facility is available.

[5] High accuracy even under most adverse environmental conditions such as dust, corrosive, heat and cold.

[6] High stability and ruggedness.

[7] High resolution.

[8] Long equipment life.

[9] No technical skill is required to operate.

[10] Great feasibility.

\section{OUTPUT TABLE}

$\begin{array}{lll}596 & 12: 20: 2919 / 03 / 2020 & 0 \\ 597 & 12: 20: 3419 / 03 / 2020 & 0 \\ 598 & 12: 20: 4019 / 03 / 2020 & 0 \\ 599 & 12: 20: 4619 / 03 / 2020 & 1 \\ 600 & 12: 20: 5119 / 03 / 2020 & 1 \\ 601 & 12: 20: 5719 / 03 / 2020 & 1 \\ 602 & 12: 21: 0219 / 03 / 2020 & 1 \\ 603 & 12: 21: 0819 / 03 / 2020 & 1 \\ 604 & 12: 21: 1319 / 03 / 2020 & 1 \\ 605 & 12: 21: 1919 / 03 / 2020 & 1 \\ 606 & 12: 21: 2419 / 03 / 2020 & 1 \\ 607 & 12: 21: 3019 / 03 / 2020 & 1 \\ 608 & 12: 21: 3519 / 03 / 2020 & 1\end{array}$

Table 1.1 outputs of the weighing scale

\section{METHODLOGY}

Load cells, one of the most utilized sensors used in weighing applications these days. The load cell can measure the electrical resistance that changes in response to the strain (e.g. pressure or force) applied to the load cell. Load cells are used for faster and most accurate measurements. If we compared the load cell with other sensors, these cells are cheaper and can be used for a longer time period. In this weighing machine one, we have used in this project is a straight bar load cell. This straight bar load cell is made up of an aluminum alloy and has the tendency of reading a capacity of $2 \mathrm{KG}$ of weight. This load cell has four lead wires which are connected to HX711 A/D Pressure Sensor.

The load cell sensor has easy installation and very simple, as shown in fig 1, the load cell has to be fixed from one end through the screw hole and the other end left floating state. In figure (the arrow) indicates the direction of the gravitational forcc.

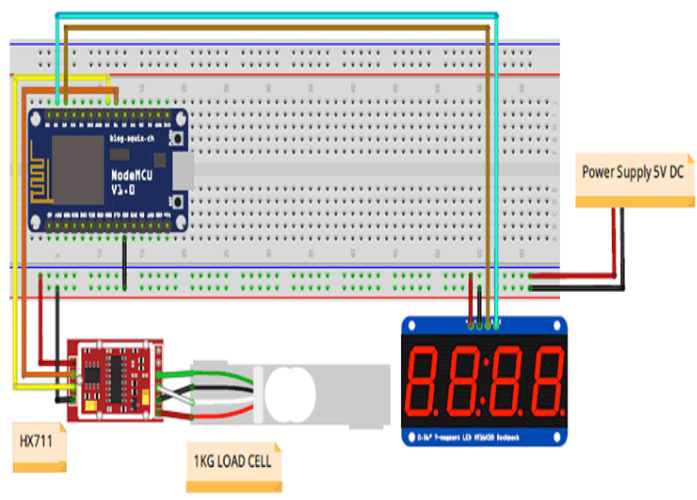

Fig 2:Circuit diagram

\section{RESULT}

After a comprehensive survey of available weighing devices to weigh sugarcanes, as we say nowadays, sugar mills used manual techniques to operate many of its functioning. Sugar Mills gave the slip to the farmers which are used for accounting the weight of the sugarcane and the price of the sugarcane so this process is time taking and if the slip got misplaced it is a very hectic process for both the parties. So, we want to automate this process by making very convenient and easy for the farmers to use.

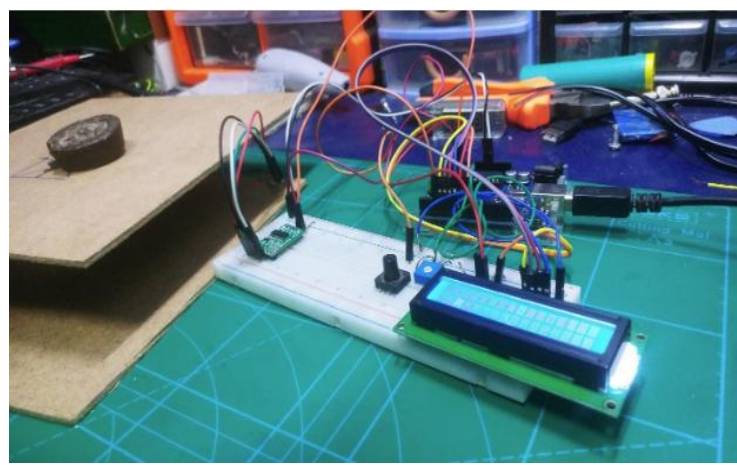

Fig 3: Implementation

Earlier, Sugar Mills weights sugarcane manually in which there is a lot of cases of fraud, So we also automate this process with the help of IoT, in this we use Arduino for weighting sugarcane and this will automatically send the details online.

It reduces hourly basis time used for recordings and also reduces site visiting. We can easily access data in few minutes. It helps to make people digitalized and easily weigh their product.

\section{CONCULSION}

The Project Design objective of providing an application for weighing sugarcane in sugar mills was successfully achieved. 
Weights sugarcane manually in which there is a lot of cases of fraud, so we automate this process with the help of the IoT weighing Scale, in this application we use Load Cell weighing and by Wi-Fi module will help to automatically update the details online. Also, I got the database server to store all intermediate results and also we can delete all results.

It is a very significant technique to weight a material through a smart weighing scale where load cells show their significant work and used as a sensor for weighing, as well as HX711 used for Wi-Fi module and on the other hand we used our server database so that we can easily see update weighing entries on our server page with timely updating result without any fraud procedure and also we can start from the beginningby only click on delete results that user weights their material easily without any fear.

\section{ACKNOWLEDGMENTS}

It gives us a great sense of pleasure to present the research paper on Design and Development of Smart Weighing scale for Sugar Mill. We owe special debt of gratitude to our guide Assistant professor Vishal Choudhary, Department of Computer Science \& Engineering, Meerut Institute of Engineering and Technology, Meerut for his constant support and guidance throughout the course of our work. His sincerity, thoroughness and perseverance have been a constant source of inspiration for us. It is only his cognizant efforts that our endeavors have seen light of the day.

\section{REFERENCES}

[1] Arasteh, H., et al. "Iot-based smart cities: a survey." Environment and Electrical Engineering (EEEIC), 2016 IEEE 16th International Conference IEEE, 2016.

[2] Zygiaris, Sotiris. "Smart city reference model: Assisting planners to conceptualize the building of smart city innovation ecosystems." Journal of the Knowledge Economy 4.2 (2013), pp. 217-231.

[3] Parkash, Prabu V. "IOT based Waste management for smart city." International Journal of Innovative Research in Computer and Communication Engineering 4.2 (2016).

[4] Garbage Management in Cities using IoT." International Journal Of Engineering And Computer Science5.11 (2016), pp. 1-3..

[5] "Sugarcane farmers": Food and Agriculture Organization of the United Nations, 2016

[6] Ciudin, Rodica, et al. "Vacuum waste collection system for an historical city centre." UPB Scientific Bulletin, Series D: Mechanical Engineering 76.3 (2014), pp. 215222

[7] Orr, Robert J., and Gregory D. Abowd. ACM, 2000, pp.' sugarcane weight, an example of an early scientific study" 275-276 